\title{
The Effect of Aerobic Exercise on Intraocular Pressure in Horse
}

\author{
Elisabetta Giudice ${ }^{1}$, Claudia Giannetto 2 , Stefania Casella ${ }^{2}$, Giuseppe Piccione ${ }^{2}$ \\ ${ }^{1}$ Department of Veterinary Public Health, Faculty of Veterinary Medicine, \\ University of Messina, Italy \\ ${ }^{2}$ Department of Experimental Sciences and Applied Biotechnology, Laboratory of Veterinary Chronophysiology, \\ Faculty of Veterinary Medicine, University of Messina, Italy \\ Received September 18, 2008 \\ Accepted June 15, 2010
}

\begin{abstract}
The present study was planned to investigate the effect of the intensity of exercise on intraocular pressure (IOP), systolic and diastolic blood pressure, glycaemia and blood lactate concentration in regularly trained Italian saddle jumper horses.

On the first day five female horses performed $1 \mathrm{~h}$ of walking on an electronically controlled horse-walker at $100 \mathrm{~m} / \mathrm{min}$; on the second day $1 \mathrm{~h}$ session consisted of 5 min of walk, 30 min of trot, $20 \mathrm{~min}$ of gallop and one exercise of a $300 \mathrm{~m}$ long trail with eight jumps $90 \mathrm{~cm}$ high to be run in 1 $\mathrm{min}$. The studied indicators were collected at rest, immediately after the exercise and $30 \mathrm{~min}$ after the exercise. Analysis of variance (ANOVA) showed a significant effect of different workloads on blood lactate concentration, systolic and diastolic blood pressure. No significant difference was found in IOP reduction when comparing aerobic and moderate anaerobic exercise.

Our results confirm that the lack of a significant change in IOP in the athletic horse after mild exercise is in accordance with the human athlete. The cardiovascular and haematological changes induced by aerobic and moderate anaerobic exercise had no significant effect on IOP, either.
\end{abstract}

\section{Different workloads, blood pressure, glycaemia, lactate}

In recent years, it has been noted that intraocular pressure (IOP) is a dynamic value and is influenced by many factors affecting both acutely and in the long term (Qureshi et al. 1996a). Several studies have shown that IOP varies with age, sex, diurnality and season (Martin 1992; Wilensky et al. 1993; Qureshi et al. 1996b).

The effects of physical exercise on IOP have received some attention in humans since the beginning of the $20^{\text {th }}$ century but definite conclusions concerning IOP changes due to exercise are not known (Moura et al. 2002). In fact, the existing literature is controversial regarding the relationship between physical fitness and IOP (D ane et al. 2006). Several studies have shown that IOP decreases in response to exercise (Kielar et al. 1975; Marcus et al. 1970a; Stewart et al. 1970; Shapiro et al. 1978). Some of them (Lempter et al. 1967; Kielar et al. 1975) have reported that this effect is inversely proportional to the work load, while others (Leighton and Philips 1970) have reported that the IOP reduction is directly related to the exercise load, even though the exercise intensities have not been standardized to the individuals. In fact, in humans the IOP decreases after a light fitness exercise and increases during a maximum effort (Avunduk et al. 1999; Qureshi et al. 1997; Dickerman et al. 1999; 2000). Other studies have shown that IOP in acute, dynamic exercise is in proportion to the relative intensity but not to the duration of the exercise (Kiuchi et al. 1994; Harris et al. 1994); yet others found either no effect on IOP or variable results (Era et al. 1993). The degree of ocular hypotensive response may vary from study to study as a result of different experimental methods, pre-study physical condition, baseline IOP, timing of pressure measurement, and diurnal variation.

Numerous systemic physiological changes that occur during exercise were proposed

Address for correspondence:

Prof. Giuseppe Piccione

Dipartimento di Scienze Sperimentali e Biotecnologie Applicate

Laboratorio di Cronofisiologia Veterinaria, Facoltà di Medicina Veterinaria

Università di Messina, Polo Universitario dell’Annunziata, 98168 Messina, Italy

Phone: +390903503584

Fax: +390903503975

E-mail: giuseppe piccione@unime.it

http://www.vfu.cz/acta-vet/actavet.htm 
as possible mechanisms for the ocular hypotensive response to exercise, although it is tempting to associate decreased IOP with intra- and post-exercise systemic haemodynamic factors, such as heart rate or elevated diastolic or systolic blood pressure (Ashkenazi et al. 1992). Some studies attempted to associate the ocular hypotensive response to exercise with increased plasma osmolarity, increased blood lactate level, and decreased $\mathrm{pH}$ level, although no significant difference was found between the IOP after aerobic exercise compared to anaerobic exercise (Keilar et al. 1975; Marcus et al. 1970a,b).

We conducted a prospective study to evaluate IOP response to two different workloads. An attempt was made to correlate determinants of aerobic exercise, such as glycaemia and blood lactate concentration with changes in IOP.

\section{Materials and Methods}

Five Italian saddle jumper horses from the same Horse Training Centre were used (Table 1). Before the start of the study, all horses underwent a heart exam, respiratory auscultation and routine haematology and plasma biochemistry at rest. Only clinically healthy animals were used. Horses were traditionally fed three times a day $(08: 00,12: 00$ and 20:00 h) with hay and a mix of cereals (oats and barley, $50 \%$ each, about 3.5 $\mathrm{kg} / \mathrm{horse} /$ day), and water ad libitum. All horses were trained appropriately from 15:00 to 16:00 h for six days a week. The training program consisted of $1 \mathrm{~h}$ of walking in a horse-walker (Tecno exerciser, Pessa Studio, Italy) at $100 \mathrm{~m} / \mathrm{min}$, electronically controlled in the morning of the first day; and of $1 \mathrm{~h}$ session of $5 \mathrm{~min}$ of walk, $30 \mathrm{~min}$ of trot, $20 \mathrm{~min}$ of gallop; 1 exercise consisted of a $300 \mathrm{~m}$ long trail with eight jumps $90 \mathrm{~cm}$ high (4 vertical jumps, 3 long jumps, and one double vertical and long jump), to be run in $1 \mathrm{~min}$ and few minutes of walk on a sand track in the morning of the second day. Samples were collected at rest, immediately after the exercise and $30 \mathrm{~min}$ after the exercise in both the experimental conditions. Blood samples were collected by means of jugular puncture with a heparinized vacutainer (Terumo Corporation, Japan) for determination of glycaemia and lactate concentration by commercially available meters (Glucotrend $2^{\circledR}$, Roche Diagnostics, Basel, Switzerland and Accusport ${ }^{\circledR}$, Boehringer, Mannheim, Germany, respectively). Diastolic and systolic blood pressure were determined with an oscillometric apparatus (Argus TM-7, Schiller, Baar, Switzerland), using a cuff positioned at the base of the tail, previously shaved; its accuracy was within $1 \mathrm{~mm} \mathrm{Hg}$. IOP values were recorded for both eyes of each animal. The first eye to be tested was randomly chosen and recorded. Oxibuprocaine chlorohydrate (Novesina $0.4 \%$, Novartis) was instilled into the eye a few seconds before being tested, and IOP was measured using a Tono-Pen Applanation Tonometer (Tono-Pen XL, Mentor Ophthalmic, USA) by the same person. The Tono-Pen tonometer had been recently calibrated by its manufacturer and was used and maintained in accordance with manufacturer's recommendations. It was gently placed on the cornea, and a Sanitized Ocu-Film tip cover was used to minimize the risk of cross contamination. Three measurements were obtained at each pressure, and mean values were calculated. Measurements were repeated until the instrument percentage error was $<5 \%$.

Table 1. Saddle jumper horse characteristics, IOP (intraocular pressure mean values between left and right eye), HR (heart rate) and BL (blood lactate) at rest, before the start of the study

\begin{tabular}{|c|c|c|c|c|c|c|c|}
\hline Horse & Breed & Age (years) & Sex & Weight $(\mathrm{kg})$ & IOP $(\mathrm{mmHg})$ & HR (bpin) & BL (mmol/l) \\
\hline 01 & Italian saddle & 9 & Female & 480 & 19.96 & 44 & 1.34 \\
\hline 02 & Italian saddle & 10 & Female & 450 & 18.22 & 30 & 1.20 \\
\hline 03 & Italian saddle & 8 & Female & 500 & 19.40 & 35 & 1.35 \\
\hline 04 & Italian saddle & 11 & Female & 530 & 18.36 & 27 & 1.50 \\
\hline 05 & Italian saddle & 10 & Female & 450 & 19.46 & 40 & 1.35 \\
\hline \multicolumn{2}{|c|}{ Mean \pm SD } & $9.6 \pm 1.1$ & & $482 \pm 34.20$ & $19.08 \pm 0.75$ & $35.20 \pm 6.97$ & $1.35 \pm 0.10$ \\
\hline
\end{tabular}

Since the intragroup variance was not significant, the statistical analysis of data was carried out on mean values of the studied indicators. The data were analyzed using the software STATISTICA 7 (StatSoft Inc.). Two-way repeated measurement of ANOVA (analysis of variance) was used to determine the influence of the experimental condition and different workloads on the indicators studied. Where ANOVA showed an acceptable level of significance $(P<0.05)$, Bonferroni's test was applied for post hoc comparison. Student's $t$-test was applied to evaluate significant differences between the two eyes. All results were expressed as means \pm standard deviation (SD). All work presented here complies with current regulations covering animal experimentation in Italy. 


\section{Results}

Two-way repeated measurement of ANOVA showed a significant effect of experimental exercise of horses on their glycaemia $\mathrm{F}_{(2,16)}=8.33, p \leq 0.001$; blood lactate $\mathrm{F}_{(2,16)}=34.63$, $p \leq 0.0001$; systolic blood pressure $\mathrm{F}_{(2,16)}=11.06, p \leq 0.001$ and diastolic blood pressure $\mathrm{F}_{(2,16)}=24.40, p \leq 0.0001$; and a significant effect of different workloads on blood lactate concentration $\mathrm{F}_{(1,16)}=55.25, p \leq 0.0001$; systolic blood pressure $\mathrm{F}_{(1,16)}=6.46, p \leq 0.01$ and diastolic blood pressure $\mathrm{F}_{(1,16)}=5.80, p \leq 0.01$. No significant effect was observed on IOP in both eyes of horses. Bonferroni's multiple comparison test showed the following significant effects of exercise: glycaemia after exercise vs. rest in both exercise sessions $(p<0.05)$; lactate in sand track session only, after exercise and after $30 \mathrm{~min}$ vs. rest $(p<0.001)$, systolic and diastolic blood pressure in sand track session only immediately after exercise vs. rest $(p<0.001)$ (Table 2). The application of Student's $t$-test showed no significant differences between the left and the right eye $(p>0.05)$.

Table 2. Mean $( \pm \mathrm{SD})$ of the indicators measured at rest, immediately after and $30 \mathrm{~min}$ after exercise in five jumper horses subjected to two different work loads carried out in the Horse-walker and Sand track, together with their significance

\begin{tabular}{|c|c|c|c|}
\hline \multirow{2}{*}{ Indicators } & & Horse-wolker & \\
\hline & Rest & After exercise & After $30 \mathrm{~min}$ \\
\hline Glycaemia (mg/dl) & $69.20 \pm 3.19$ & $63.00 \pm 4.58^{\diamond}$ & $64.20 \pm 4.43$ \\
\hline Lactate $(\mathrm{mmol} / \mathrm{l})$ & $1.36 \pm 0.20$ & $1.26 \pm 0.15^{\mathrm{b}}$ & $1.26 \pm 0.11$ \\
\hline IOP left eye $(\mathrm{mmHg})$ & $19.64 \pm 2.02$ & $18.02 \pm 1.65$ & $18.72 \pm 1.94$ \\
\hline IOP right eye $(\mathrm{mmHg})$ & $19.32 \pm 1.97$ & $18.62 \pm 2.28$ & $19.14 \pm 0.44$ \\
\hline Systolic blood pressure $(\mathrm{mmHg})$ & $128.70 \pm 5.09$ & $141.52 \pm 11.32^{\mathrm{a}}$ & $135.20 \pm 12.13$ \\
\hline \multirow[t]{2}{*}{ Diastolic blood pressure $(\mathrm{mmHg})$} & $98.45 \pm 9.58$ & $112.09 \pm 7.73^{\mathrm{a}}$ & $96.00 \pm 5.38$ \\
\hline & & Sand Track & \\
\hline Glycaemia (mg/dl) & $69.14 \pm 4.99$ & $61.80 \pm 5.35^{\diamond}$ & $62.00 \pm 5.87$ \\
\hline Lactate $(\mathrm{mmol} / \mathrm{l})$ & $1.32 \pm 0.08$ & $3.14 \pm 0.47^{\circ b}$ & $1.35 \pm 0.31^{\circ}$ \\
\hline IOP left eye $(\mathrm{mmHg})$ & $19.17 \pm 0.55$ & $17.90 \pm 1.24$ & $18.76 \pm 1.47$ \\
\hline IOP right eye $(\mathrm{mmHg})$ & $18.80 \pm 1.35$ & $17.72 \pm 1.21$ & $18.66 \pm 1.02$ \\
\hline Systolic blood pressure $(\mathrm{mmHg})$ & $132.48 \pm 9.33$ & $135.04 \pm 8.24^{\circ \mathrm{a}}$ & $140.90 \pm 6.59$ \\
\hline Diastolic blood pressure $(\mathrm{mmHg})$ & $90.14 \pm 7.42$ & $125.00 \pm 0.28^{\circ \mathrm{a}}$ & $108.53 \pm 3.22$ \\
\hline
\end{tabular}

Significance: ${ }^{\circ}$ vs. rest $p<0.05 ;{ }^{\circ}$ vs. rest $p<0.0001$

Significant effect of different work load: ${ }^{\mathrm{a}} p<0.01 ;{ }^{\mathrm{b}} p<0.0001$

\section{Discussion}

Dynamic exercise is characterized by short periods of contraction alternated with periods of relaxations. In this kind of exercise there are numerous systemic physiological changes that can be categorized as to the intensity of the workload. It was observed that the intensity of workload can influence the haematological indicators useful in the assessment of the fitness of sport horses and aerobic working capacity (Piccione et al. 2007a), the hydration status and the electrolyte balance (Piccione et al. 2007b).

Blood lactate concentration, systolic blood pressure and diastolic blood pressure were significantly increased by exercise, in accordance with other studies carried out in horse and were affected by different workloads (Attanzio et al. 2001).

Blood lactate concentration was influenced by the effect of experimental conditions only during the session carried out on the sand track. This had strengthened the existence of a different workload in the exercise given to the horse. Therefore, the workload intensity on the horse-walker can be classified as a nearly alactacidaemic level (blood lactate mean concentration: $1.26 \pm 0.15 \mathrm{mmol} / \mathrm{l}$ ) of exercise performed in perfect respiratory conditions 
and humoral state; whereas the exercise on the sand track can be classified as a moderate anaerobic exercise level (blood lactate mean concentration: $3.14 \pm 0.47 \mathrm{mmol} / \mathrm{l}$ ), performed in a respiratory steady-state, with a considerable lactacidaemia, that did not reach the anaerobic threshold value (Sevdahl and Maclntosh 2003).

The significant rise in blood pressure due to exercise might have been paralleled by an increase in ocular tension. In fact, it is known that a rise in ocular tension can result from an increase in the venous pressure (Bain and Maurice 1959; Comberg and Pilz 1961). However, our results did not show a significant decrease of IOP after exercise. This suggests that the value of IOP after exercise are not closely related to the blood pressure variations, but are influenced by cardiovascular and haematological adaptations necessary to guarantee the correct oxygen and blood-borne substrate supply to activate muscles during exercise and the release of metabolites.

Certain inverse relationship has been found between osmolarity and IOP, and these changes in IOP have been attributed to serum lactate or blood pH (Marcus et al. 1974; Qureshi 1995; Martin et al. 1999). Lactate-induced decrease in IOP after exercise appears to be due to the rise in plasma osmolarity rather than the elevation of lactate itself (Marcus et al. 1970a). In association with the rise in blood lactate other factors play a role in increasing plasma osmolarity after acute exercise: sweating with resultant water loss; increased blood pressure in capillaries which is associated with the rise in systolic blood pressure and movement of fluid from the blood into tissue spaces; and an increase in intracellular osmolarity due to increased metabolism which leads to osmotic absorption of fluid into the cells (Morehouse and Miller 1963).

In a previous study (Piccione et al. 2007b), the same exercise carried out on a horsewalker and sand track determined a significant change of sodium, chloride, potassium, calcium, magnesium, total protein and haematocrit values with a significant effect of different workloads due to fluid movement following exercise. Based on these results we can suppose that the loss of water and electrolytes that occurs during aerobic exercise did not cause changes in IOP.

In conclusion, our results are in accordance with those of Shapiro et al. (1978) showing in human athlete that when the exercise is mild, IOP may not change significantly. We may also conclude that cardiovascular and haematological changes induced by aerobic and moderate anaerobic exercise had no significant effect on IOP. In fact in the present study blood lactate level and blood pressure were significantly different between rest and exercise, but no significant differences in IOP were found between exercising and resting conditions.

\section{References}

Ashkenazi I, Melamed S, Blumenthal M 1992: The effect of continuous strenuous exercise on intraocular pressure. Invest Ophthalmol Vis Sci 10: 2874-2877

Attanzio G, Assenza A, Piccione G, Caola G 2001: Influence of the blood lactate on the short time control of the blood pressure in the jumper horse. Atti Soc It Sci Vet 55: 65-66

Avunduk AM, Yilmaz B, Sahin N, Kapcioglu Z, Dajanir V 1999: The comparison of intraocular pressure reductions after isometric and isokinetic exercises in normal individuals. Ophthalmol 213: 290-294

Bain WES, Maurice DM 1959: Physiological variations in the intra-ocular pressure. Trans Ophthalmol Soc UK 79: $249-60$

Comberg D, Pilz A 1961: Intraocular pressure and rigidity reaction in experimental increase in venous pressure. Graefes Arch Clin Exp Ophthalmol 163: 189-202

Dane S, Kocer I, Demirel H, Ucok K, Tan U 2006: Effect of acute submaximal exercise on intraocular pressure in athletes and sedentary subjects. Int J Neurosci 116: 1223-1230

Dickerman RD, Smith GH, Langham-Roof L, McConathy WJ, East JW, Smith AB 1999: Intra-ocular pressure changes during maximal isometric contraction: does this reflect intra-cranial pressure or retinal venous pressure? Neurol Res 21: 243-246

Dickerman RD, McConathy WJ, Smith GH, East JW, Rudder L 2000: Middle cerebral artery blood flow velocity in elite power athletes during maximal weight-lifting. Neurol Res 22: 337-340 
Era P, Parssinen O, Kallinen M 1993: Effect of bicycle ergometer test on intraocular pressure in elderly athletes and controls. Acta Ophthalmol Scand 71: 301-307

Harris A, Malinovsky V, Martin B 1994: Correlates of acute exercise-induced ocular hypotension. Invest Ophthalmol Vis Sci 35: 3852-3857

Kielar RA, Teraslinna P, Row DG, Jackson J 1975: Standardized aerobic and anaerobic exercise: Differential effect on intraocular tension, blood $\mathrm{pH}$ and lactate. Invest Ophthalmol 14: 782-785

Kiuchi Y, Mishima Hk, Hotehama Y, Furumoto A, Hirota A, Onari K 1994: Exercise intensity determines the magnitude of IOP decrease after running. Jpn J Ophthalmol 38: 191-195

Leighton DA, Philips CI 1970: Effect of moderate exercise on the ocular tension. Br J Ophthalmol 54: 599-605

Lemper P, Cooper K, Culver JF, Tredici TJ 1967: The effect of exercise on intraocular pressure. Am J Ophthalmol 63: $1673-1676$

Marcus DF, Krupin T, Podos SM, Becker B 1970a: The effect of exercise on intraocular pressure: II. Rabbits. Invest Ophthalmol 9: 753-757

Marcus DF, Krupin T, Podos SM, Becker B 1970b: The effect of exercise on intraocular pressure: I. Human being. Invest Ophthalmol 9: 749-752

Marcus DF, Edelhauser HF, Maksud MG, Wiley RL 1974: Effects of a sustained muscular contraction on human intraocular pressure. Clin Sci Mol Med 47: 249-257

Martin XD 1992: Normal intraocular pressure in man. Ophthalmol 205: 57-63

Martin B, Harris A, Hammel T, Malinovsky V 1999: Mechanism of exercise-induced ocular hypotension. Inv Ophthalmol Vis Sci 40: 1011-1015

Morehouse LE, Miller AT 1963: Physiology of Exercise. The CV Mosby Company, St Louis, 131 p.

Moura MA, Rodrigues LOC, Waisberg Y, De Almeida HG, Silami-Garcia E 2002: Effects of submaximal exercise with water ingestion on intraocular pressure in healthy human males. Braz J Med Biol Res 35: 121-125

Piccione G, Giannetto C, Fazio F, Di Mauro S, Caola G 2007a: Haematological response to different workload in jumper horse. Bulgarian J Vet Med 10: 21-28

Piccione G, Giannetto C, Assenza A, Fazio F, Caola G 2007b: Serum electrolyte and protein modification during different workload in jumper horse. Comp Clin Pathol 16: 103-107

Qureshi IA 1995: Effects of mild, moderate and severe exercise on intraocular pressure of sedentary subjects. Ann Human Biol 22: 545-553

Qureshi IA 1997: Does physical fitness influence intraocular pressure? J Pak Med Assoc 47: 81-84

Qureshi IA, Hi AR, Huang YB, Wu XD 1996a: Magnitude of decrease in intraocular pressure depends upon intensity of exercise. Korean J Ophthalmol 10: 109-115

Qureshi IA, Xi XR, Lu HJ, Wu XD, Huang YB, Shiarkar E 1996b: Effect of seasons upon intraocular pressure in healthy population of China. Korean J Ophthalmol 10: 29-33

Sevdahl K, MacIntosh BR 2003: Anaerobic threshold: the concept and methods of measurement. Can J Apll Physiol 28: 299-323

Shapiro A, Shoenfeld Y, Shapiro Y 1978: The effect of standardised submaximal work load on intraocular pressure. British J Ophthalmol 62: 679-681

Stewart RH, Leblanc R, Becker B 1970: Effect of exercise on aqueous dynamics. Am J Ophthalmol 69: 245-248

Wilensky JT, Gieser DK, Dietsche ML 1993: Individual variability in the diurnal intraocular pressure curve. Ophthalmol 100: 940-944 
